\title{
The Most Important Risk Factors Affecting the Physical Health of Orthodontists: A Pilot Study
}

\author{
Giedre Trakiniene*, Monika Rudzinskaite, Greta Gintautaite and Dalia Smailiene
}

Citation: Trakiniene, G.; Rudzinskaite, M.; Gintautaite, G.; Smailiene, D. The Most Important Risk Factors Affecting the Physical Health of Orthodontists: A Pilot Study. Appl. Sci. 2022, 12, 1087. https://doi.org/10.3390/ app12031087

Academic Editor: Ivana Miletić

Received: 25 October 2021

Accepted: 13 December 2021

Published: 20 January 2022

Publisher's Note: MDPI stays neutral with regard to jurisdictional claims in published maps and institutional affiliations.

Copyright: (C) 2022 by the authors. Licensee MDPI, Basel, Switzerland. This article is an open access article distributed under the terms and conditions of the Creative Commons Attribution (CC BY) license (https:// creativecommons.org/licenses/by/ $4.0 /)$.
Clinic of Orthodontics, Medical Academy, Lithuanian University of Health Sciences, 50140 Kaunas, Lithuania; rudzinskaite.monika@stud.lsmu.lt (M.R.); gintautaite.greta@stud.lsmu.lt (G.G.); dalia.smailiene@lsmuni.lt (D.S.)

* Correspondence: giedre.trakiniene@lsmuni.lt

\begin{abstract}
The purpose of this study is to evaluate the most frequent problems in the physical health of orthodontists and to determine which factors in the working environment of dental specialists have the most important influence on the physical health of orthodontic practitioners. This survey was conducted using a questionnaire that was distributed among orthodontists and dental specialists. The questionnaire consisted of 42 questions: 36 closed-ended questions with 1 or multiple possible answer choices, and 6 open-ended questions. The survey was carried out online and responses were collected anonymously. The study included 266 questionnaires completed by orthodontists and dental practitioners with a mean age of $34.5 \pm 10.1$ years. The results showed that $71 \%$ of orthodontists and $90 \%$ of dental practitioners experienced different types of pain during their workday and after work. The most common health problems among orthodontists were shoulder and neck pain. Orthodontists' health status was better than dentists'. Usually, orthodontists experience shoulder and neck pain. The factors that helped orthodontists avoid health disorders were: the use of individually adjustable backrests and saddle-type chairs, assuming a neutral sitting position, keeping work equipment as close as possible, and breaks in between patients during work.
\end{abstract}

Keywords: orthodontist; chairside time; ergonomics in orthodontics; neutral sitting position

\section{Introduction}

The scope of ergonomics in dentistry is to reduce cognitive and physical stress, prevent occupational diseases related to the practice of dentistry, and improve productivity, with better quality and greater comfort for both the professional and the patient [1,2]. The dental profession and orthodontics are not an exception. They are recognized as challenging, due to numerous occupational health hazards, which can be grouped into biological, biomechanical, physical, and psychological [3].

Direct contact with patients and contamination with saliva and blood determine the high risk of infectious diseases among dental professionals: they have a high risk of becoming infected with hepatitis B and C viruses, HIV (human immunodeficiency virus), or tuberculosis. Face-to-face communication and consistent exposure to body fluids put dental care workers at serious risk of 2019-nCoV infection [4]. Sensory system disorders may occur because of dental equipment properties and medicines used. Allergies and skin lesions are also frequent because of the materials used in daily practice. Moreover, a high level of long-lasting physical stress during working hours in a non-ergonomic posture can be the reason for various musculoskeletal and peripheral nervous system disorders $[5,6]$.

Musculoskeletal disorders and pain are some of the most common ailments dentists face in their work. Based on whole world research data, 96.9\% of surveyed dentists in the Czech Republic, $82.6 \%$ in Serbia, $81.4 \%$ in Brazil, $80 \%$ in the Netherlands, and 79.8\% in Slovenia have musculoskeletal system pain [7-11]. Dental professionals are prone to musculoskeletal disorders, especially neck and back pain, owing to the following risk factors as a part of their practice repetitive movements, maintenance of awkward body 
postures for long periods of static postures, and tasks that require fine motor skills and close visual focus [12].

The main areas of the body that could be damaged during the dentist's work are the neck, shoulder girdle, upper and lower back, arms, and wrists [12]. Pejčić et al. found that more than $80 \%$ of dentists experienced neck and shoulder pain during or after work $[8,13]$. Another vulnerable area of the body in the work of a dentist is hands and wrists. The main causes of this pain were repetitive hand movements when manipulating instruments and the need for high hand force during certain dental procedures, such as tooth extraction, cleaning tartar, or braces removal [14].

Thus, this research topic was chosen to take into account the accelerating pulse of life, which also affects the pace of work. The purpose of this study is twofold: first, to evaluate the most frequent problems in the physical health of orthodontists; second, to find out which factors in the working environment of dental specialists have the most important influence on the physical health of orthodontic practitioners.

The hypothesis of this research is that the physical health of orthodontists is the same as that of dentists.

\section{Materials and Methods}

The study was performed in accordance with relevant ethical guidelines and regulations during the period from August 2019 to March 2020. Approval for the research was obtained from the University of Health Sciences Biomedical Research Committee. The sample size calculation was based on the following formula:

$$
n=\frac{1}{\Delta^{2}+\frac{1}{N}}
$$

where $n$-the minimum sample size for each sample; $N$ — the population size; and $\Delta$ - the smallest clinically important difference. The minimal calculated study sample was 102 .

The inclusion criteria were: (1) practicing general dentists and orthodontists; and (2) all questions in the questionnaire were answered. The research method was a questionnaire survey. The research questionnaire was posted on the website https://apklausa.lt (accessed on 10 August 2019). It was anonymous and the confidentiality of the respondents was ensured.

\subsection{Questionnaire}

The questionnaire was developed after the revision of previous studies and adapted to the research contingent $[8,15]$. The reliability of the questionnaire was estimated by the use of Cronbach's alpha (0.81).

The questionnaire consisted of a total of 42 questions. Six open-ended and closedended questions were designed to gather general information about respondents: their gender, age, place of work, qualifications, and work experience. The 3 open-ended questions were designed to find out the workload of the dental specialist in terms of working hours. The eleven closed-ended questions were designed to assess dental specialists' attitudes towards their work and their personal self-assessment of their health status. A scale type 1 question was asked to help specialists indicate how often they experience certain ailments during and after work. The five questions were about doctors' leisure, sports, and harmful habits. At the end of the questionnaire, 14 questions were about the ergonomic working conditions of dental specialists and the application of ergonomic standards in everyday practice, which were translated from the studies of Pejčić and Sakzewski [8,15].

\subsection{Statistical Analysis}

The data was processed by IBM SPSS Statistics (Statistical Package for Social Sciences, version 17) and Microsoft Office Excel 2013. Chi-square ( $\chi 2)$ and ANOVA tests were used to determine statistically significant differences in results. A $p$-value of 0.05 was considered significant. 


\section{Results}

The study sample consisted of 266 respondents with a mean age of $34.5 \pm 10.1$ years. A total of 275 questionnaires were included in the study; 9 questionnaires were excluded because not all questions were answered. A total of $82.2 \%$ of respondents were women, and $17.8 \%$ were men. The Kolmogorov-Smirnov test for normality showed the normal distribution of the data.

More than half (58.2\%) of the respondents worked in the private sector, $15.3 \%$-in public institutions, and $27.5 \%$ both in private and public institutions. The study involved 2 groups: the group of orthodontists (105 orthodontists) and the control group of general dentists (161 dentists). The majority of the study participants ( $42 \%$ of dentists and 30\% of orthodontists) had up to 5 years of work experience; $25.6 \%$ of dentists and $42.5 \%$ of orthodontists had experience of $5-10$ years; and $32.4 \%$ of dentists and $27.5 \%$ of orthodontists had been working for more than 10 years (Figure 1).

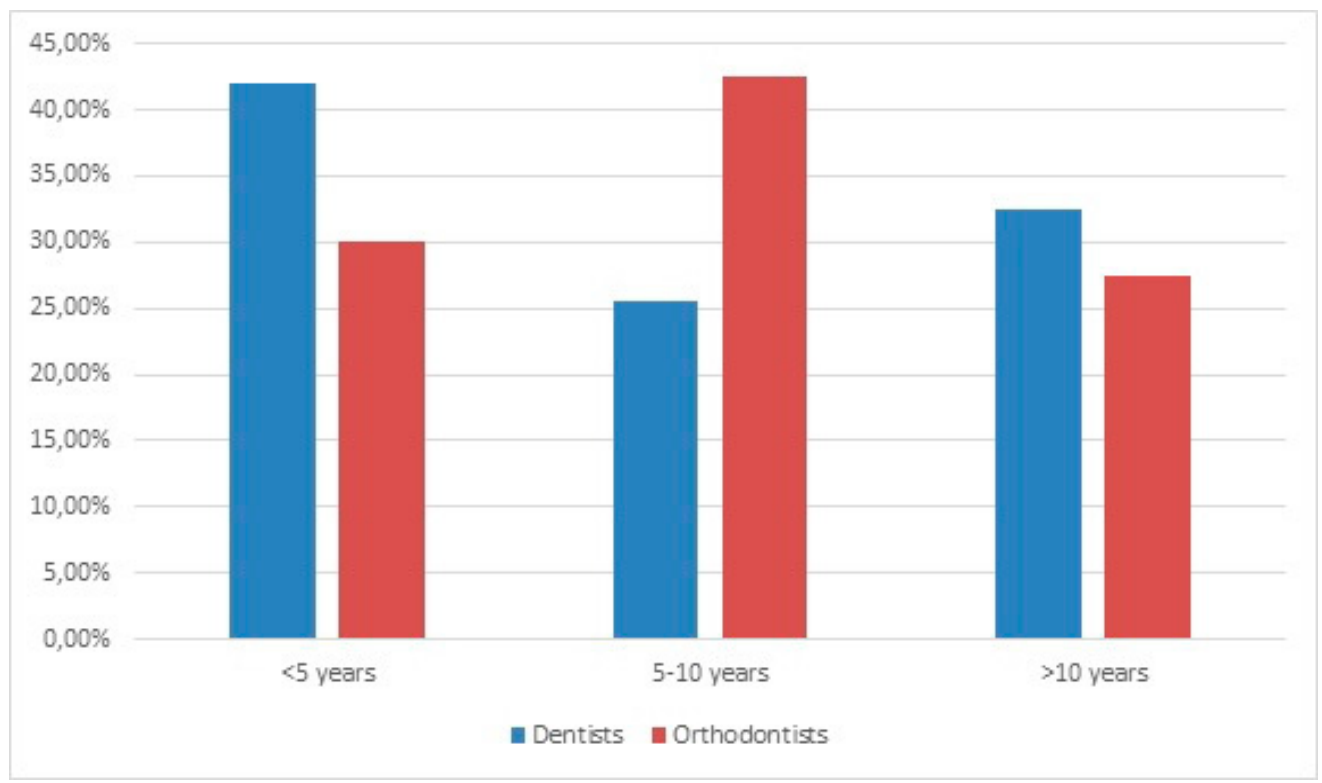

Figure 1. Distribution of respondents' work experience.

All 266 respondents believed that their work required great attentiveness. The majority of respondents $(77.8 \%)$ considered the work of a dentist to be physically difficult; $11.6 \%$ of respondents doubted whether their work was physically difficult; and $10.6 \%$ denied that the work of a dentist was physically difficult for them. The work of a dentist was physically more difficult for women than for men $(p<0.001)$. The average working time was $35.7 \pm 8.9 \mathrm{~h}$ per week.

\subsection{The Health Status of Dentists and Orthodontists}

A total of $14.3 \%$ of dentists indicated that they were in very good health. More than half $(57.9 \%)$ of respondents thought that their health was good, while $24.6 \%$ of respondents stated that their health condition was average, and 3.2\% indicated that their health was poor. Statistically, the worst current health condition was indicated by respondents who had been working as dentists for more than 10 years $(p=0.008)$. Dentists mostly had diseases of the musculoskeletal system (24.4\%) and respiratory system (20.4\%).

Orthodontists pointed out that their health was very good in $25.2 \%$ of cases; good health was in more than half of the answers $(63.8 \%)$, and $21 \%$ of orthodontists had an average health status.

Almost half of the respondents ( $47.9 \%$ of dentists and $49.3 \%$ of orthodontists) actively spent their free time, and $52.1 \%$ of dentists and $50.7 \%$ of orthodontists were passive. 
Dentists, who played sports, reported having a better health status than those who did not engage in sports $(p<0.001)$.

Only one-third of respondents ( $28.9 \%$ of dentists and $13.2 \%$ of orthodontists) often experienced pain during work, the others ( $61.3 \%$ of dentists and $57.8 \%$ of orthodontists) experienced pain only sometimes, and $9.7 \%$ of dentists and $29 \%$ of orthodontists never had such complaints. Pain was more frequent among dentists and orthodontists working for more than 10 years $(p=0.012)$. The most common problems faced by dentists every day or at least once per week were general physical $(61.3 \%)$, eye fatigue $(48.9 \%)$, back $(51.7 \%)$, shoulder girdle $(45.4 \%)$, and neck $(44.8 \%)$ pain. In contrast, orthodontists had general physical $(43.3 \%, p=0.027)$, back $(35.5 \%, p=0.033)$, shoulder girdle $(32.5 \%, p=0.023)$, and neck pain $(31.5 \%, p=0.017)$ less frequently (Table 1$)$.

Table 1. Frequency of pain and ailments experienced by dentists and orthodontists during and after work.

\begin{tabular}{|c|c|c|c|c|c|c|c|c|c|c|c|c|}
\hline Problem & 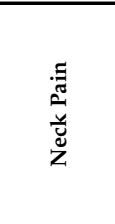 & 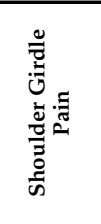 & 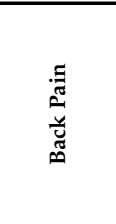 & 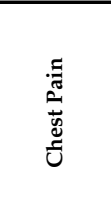 & 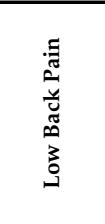 & 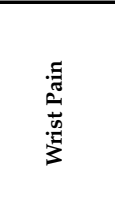 & 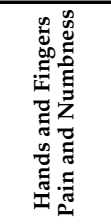 & 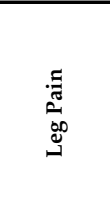 & 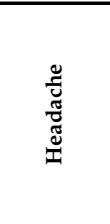 & 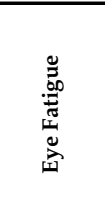 & 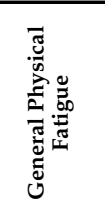 & 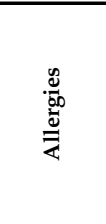 \\
\hline $\begin{array}{c}\text { Every day, } \\
\mathrm{n}(\%)\end{array}$ & $38(12.1)$ & $48(15.2)$ & $51(16.2)$ & $4(1.3)$ & $32(10.2)$ & $12(3.8)$ & $12(3.8)$ & $10(3.2)$ & $9(2.9)$ & $62(19.7)$ & $64(20.3)$ & $20(6.3)$ \\
\hline $\begin{array}{c}\text { At least once } \\
\text { a week, } \\
\text { n }(\%)\end{array}$ & $103(32.7)$ & $95(30.2)$ & $112(35.6)$ & $13(4.1)$ & $67(21.3)$ & $34(10.8)$ & $30(9.5)$ & $19(6.0)$ & $95(30.2)$ & $92(29.2)$ & $129(4.0)$ & $12(3.8)$ \\
\hline $\begin{array}{c}\text { Less than once } \\
\text { a week, } \\
\text { n }(\%)\end{array}$ & $63(20.0)$ & $67(21.3)$ & $68(21.6)$ & $28(8.9)$ & $80(25.4)$ & $51(16.2)$ & $33(10.5)$ & 37 (11.7) & $112(35.6)$ & $87(27.6)$ & $76(24.1)$ & $27(8.6)$ \\
\hline $\begin{array}{l}\text { Less than once } \\
\text { a month, } \\
\text { n (\%) }\end{array}$ & $74(23.5)$ & $73(23.2)$ & $69(21.9)$ & $64(20.3)$ & 75 (23.8) & $128(40.6)$ & $111(35.2)$ & 99 (31.4) & $74(23.5)$ & $51(16.2)$ & $41(13.0)$ & $78(24.8)$ \\
\hline $\begin{array}{c}\text { Never } \\
\text { encountered, } \\
\mathrm{n}(\%)\end{array}$ & 37 (11.7) & $32(10.2)$ & $15(4.8)$ & $206(65.4)$ & $61(19.4)$ & $90(28.6)$ & $129(41.0)$ & $150(47.6)$ & $25(7.9)$ & $23(7.3)$ & $5(1.6)$ & $178(56.5)$ \\
\hline \multicolumn{13}{|c|}{$\mathrm{N}$-number of cases } \\
\hline
\end{tabular}

In addition, subjects also reported relatively frequent lumbar pain $(31.4 \%$ of dentists and $15 \%$ of orthodontists, $p=0.026$ ) and headaches (about $33 \%$ in both groups). Wrist, hand, and leg pain were less common problems among dentists and orthodontists. Chest pain was the least frequently reported problem, with $65.4 \%$ of dentists and $66.9 \%$ orthodontists not experiencing this pain during or after work.

The experience of allergies on a daily basis reached only $6.3 \%$ among dentists and $1.2 \%$ among orthodontists $(p=0.006)$.

\subsection{Peculiarities of Ergonomics in the Work of Dental Specialists}

These peculiarities involve the most important ergonomic factors for the health of dental specialists: the working position of the specialists, work chair type, position of the working tools, and breaks during the working day.

The majority of dentists $(82.8 \%$ ) were more likely to work while sitting in a reclining chair, while the others $(17.2 \%)$ chose a standing position while the patient was sitting in a chair. A total of $98.5 \%$ of orthodontists usually worked in a sitting position, and only $1.5 \%$ preferred to work in a standing position. Dentists and orthodontists who worked in a sitting position were less likely to experience back pain during work $(p=0.006)$.

The most popular work chairs in both groups were individually adjustable with a backrest and saddle type. Dentists and orthodontists who used an individually adjustable chair with a backrest experienced back pain during work significantly less than specialists who used other types of chairs $(p=0.006)$. They also experienced fewer shoulder girdles $(p=0.008)$ and neck pain $(p=0.003)$. In addition, orthodontists experienced less frequent shoulder girdle pain using a saddle-type chair during work $(p=0.002)$. The use of 
a non-adjustable chair especially increased the risk of back $(p=0.002)$ and shoulder girdle $(p=0.015)$ pain. It was found that respondents who indicated that their office chair moved smoothly in the work area had a lower incidence of back pain $(p=0.004)$.

The majority of dentists $(67.9 \%)$ and orthodontists $(85.5 \%, p=0.027)$ kept their working tools at a distance of $40-50 \mathrm{~cm}$ from themselves, whilst $18.1 \%$ of dentists and $14.5 \%$ of orthodontists held them closer than $20 \mathrm{~cm}$. The other dentists placed the necessary tools more than $70 \mathrm{~cm}$ away from them. It was found that both dentists and orthodontists who kept the tools close to themselves were less likely to experience back $(p=0.016)$ and shoulder girdle pain $(p=0.039)$. While sitting, $43.3 \%$ of dentists and $29 \%$ of orthodontists considered the elbow joints to be bent less than 90 degrees at work and more frequently experienced neck $(p=0.007)$, shoulder girdle $(p=0.008)$, and lumbar $(p=0.006)$ pain than those specialists who bent elbow joints at 90 degrees.

Only $9.7 \%$ of dentists and $11.5 \%$ of orthodontists took their rest breaks after each patient, and about $30 \%$ of respondents had them several times a day. Others took breaks only occasionally ( $50.4 \%$ of dentists and $58.5 \%$ of orthodontists) or even did not take them (10.1\% of dentists) at all. Specialists who took breaks between patients had statistically significantly less pain during and after work $(p=0.003)$. Even short breaks significantly reduced pain in neck $(p=0.003)$, shoulder girdle $(p=0.004)$, back $(p=0.005)$, chest $(p=0.001)$, lumbar $(p=0.01)$, hands and fingers $(p=0.019)$, eye $(p=0.001)$, and total physical fatigue $(p=0.002)$.

These previously mentioned ergonomic factors caused changes in the natural position of dental specialists and affected their physical health. For example, almost half of the surveyed dentists $(49.3 \%)$ and $36.8 \%$ of orthodontists held the hip joints at a 90 degrees angle during work, others bent the hips at an angle greater or smaller than 90 degrees. Keeping the hips at an angle of less than 90 degrees exacerbated the experience of shoulder girdle pain $(p=0.012)$. The same tendency was found with the knee joint position. Dental practitioners $(18.1 \%)$ and $5.6 \%$ of orthodontists who kept their knee joints bent at an angle of less than 90 degrees during work suffered from back $(p=0.001)$, shoulder girdle pain $(p<0.001)$, and lower back pain $(p=0.049)$ more frequently than colleagues who bent their knees at 90 or 100 degrees.

Respondents believed that pain and ailments could be caused by static and prolonged awkward positions, long working hours due to a desire to ensure the most comfortable treatment position for the patient, work without an assistant, and low physical activity after work.

\section{Discussion}

The objective of this study was to evaluate the most common health disorders among orthodontists and dental practitioners and to distinguish the factors responsible for their appearance. The hypothesis of this study was supported.

The results of this study showed that about $71 \%$ of orthodontists experienced pain in various areas of their bodies during and after work. These findings were lower than in the case of other dental practitioners, in which they varied from $79.8 \%$ to $90.32 \%[8,9,11,12]$. Moreover, these results differed from the findings of Ramírez-Sepúlveda et al. [16], who investigated the population of Colombian orthodontists who had an $80 \%$ prevalence of musculoskeletal disorders (MSDs). This can be explained by paying more attention to the ergonomic factors in the workplace, such as maintaining a neutral sitting position, keeping work equipment as close as possible, and breaks between patients during work.

Moreover, our research found that orthodontists with work experience longer than 10 years experienced health disorders more often. Back, shoulder girdle, and neck were identified as the areas of the body about which practitioners complained the most.

In addition, the study found that back pain was less common among orthodontists who worked in a sitting position than those who preferred working standing. The use of individually adjustable chairs with back support and saddle-type chairs at work was found to reduce the frequency of back pain. These findings match with the study of De Bruyne et al. 
who stated that the use of a saddle-type chair in everyday practice significantly reduces low back pain [17]. In addition, the use of a saddle-type chair during work significantly reduced the incidence of shoulder girdle pain [18].

Another aspect of this research was the position of an orthodontist in daily dental practice. The findings showed that orthodontic specialists who were working in the neutral sitting position had better health than those who worked in a standing posture. In a neutral sitting position, the forearm must be kept parallel to the floor during work, and the hip and knee joints must be bent at an angle of at least 90 degrees [19]. Orthodontists who indicated that they kept the hip joints at an angle of less than 90 degrees while sitting were more likely to experience shoulder girdle pain. In addition, specialists who bent their knee joints too much during their work experienced back, shoulder girdle, and lumbar pain.

Furthermore, the positioning of dental tools is a critical factor in the musculoskeletal health of orthodontic practitioners. Our study found that specialists who kept their dental equipment at a distance of less than $50 \mathrm{~cm}$ from themselves were less likely to experience back and shoulder pain. This distance was optimal for avoiding physical stress during working hours [20].

The most significant factor that had the greatest impact on the incidence of occurrence of pain during clinical work was the frequency of breaks during the course of the workday. Orthodontists should take frequent, albeit short, breaks, as they significantly reduce the incidence of neck, shoulder girdle, back, chest, lumbar, hand, and finger pain, and also alleviate the experience of general physical and eye fatigue $[8,21,22]$.

Finally, it is believed that new orthodontic technologies can help to secure a practitioner's health by minimizing chairside time. For example, shortened chairtime appears to be one of the main reasons for the relatively high frequency of self-ligating vs. conventional ligating brackets or indirect bonding application by clinicians currently $[23,24]$.

However, Glisic stated that chairside time was equal for intraoral scan and alginate impression and required more computer work, which can cause eye fatigue, as was seen in the group of general dental practitioners [24]. Bud et al. reported that the use of loupes had primary benefits for ergonomics and posture, but a lack of fixed position disturbed the image of the magnified operating field. In contrast, work with a dental microscope required minimum adjustment and enhanced posture of the doctor [25]. Thus, chairside time may not be the only factor to consider before implementing new techniques in practice.

\section{Conclusions}

The health status of orthodontists was better than that of dentists. Usually, orthodontists experience shoulder and neck pain. The factors that helped to avoid health disorders in orthodontic specialists were the use of individually adjustable backrests and saddle-type chairs, maintaining a neutral sitting position, keeping work equipment as close as possible, and breaks between patients during work. The main limitation of this study was a small sample size. Thus, future research with larger data should be conducted for the evaluation of the effect of new technologies, such as self-ligating or indirect bonding effects on the health of orthodontists.

Author Contributions: Conceptualization, G.T. and M.R.; methodology, G.G.; validation, G.T., M.R. and D.S.; formal analysis, G.T.; investigation, M.R.; resources, G.T.; data curation, G.T.; writing—original draft preparation, G.G. and G.T.; writing—review and editing, D.S. and M.R..; supervision, D.S. All authors have read and agreed to the published version of the manuscript.

Funding: This research received no external funding.

Institutional Review Board Statement: Not applicable.

Informed Consent Statement: Informed consent was obtained from all subjects involved in the study.

Data Availability Statement: Data may be available under reasonable request. 
Acknowledgments: We would like to thank the Lithuanian University of Health Sciences for the covering the publication costs.

Conflicts of Interest: The authors declare no conflict of interest.

\section{References}

1. Gupta, A.; Ankola, A.V.; Hebbal, M. Dental Ergonomics to Combat Musculoskeletal Disorders: A Review. Int. J. Occup. Saf. Ergon. 2013, 19, 561-571. [CrossRef]

2. Gupta, A.; Bhat, M.; Mohammed, T.; Bansal, N.; Gupta, G. Ergonomics in Dentistry. Int. J. Clin. Pediatr. Dent. 2014, 7, 30-34. [CrossRef] [PubMed]

3. Vodanović, M.; Galić, I.; Kelmendi, J.; Chalas, R. Occupational health hazards in contemporary dentistry-A review. Rad Hrvat. Akad. Znan. Umjetnosti. Med. Znan. 2017, 44, 25-41. [CrossRef]

4. D'Amico, C.; Bocchieri, S.; De Stefano, R.; Gorassini, F.; Surace, G.; Amoroso, G.; Scoglio, C.; Mastroieni, R.; Gambino, D.; Amantia, E.M.; et al. Dental Office Prevention of Coronavirus Infection. Eur. J. Dent. 2020, 14, S146-S151. [CrossRef]

5. Fallahi, H.R.; Keyhan, S.O.; Zandian, D.; Kim, S.G.; Cheshmi, B. Being a front-line dentist during the COVID-19 pandemic: A literature review. Maxillofac. Plast. Reconstr. Surg. 2020, 42, 12. [CrossRef]

6. Zeinabadi, M.S.; Safaian, G.; Mirmohammadkhani, O.; Mirmohammadkhani, M.; Ameli, N. Evaluation of Health-Related Quality of Life among Dentists in Semnan, Iran, 2015-2016. Middle East J. Rehabil. Health Stud. 2018, 5, e83626.

7. Vodanović, M.; Sović, S.; Galić, I. Occupational Health Problems among Dentists in Croatia. Acta Stomatol. Croat. 2016, 50, 310-320. [CrossRef]

8. Pejčić, N.; Petrović, V.; Marković, D.; Miličić, B.; Dimitrijević, I.; Perunović, N.; Čakić, S. Assessment of risk factors and preventive measures and their relations to work-related musculoskeletal pain among dentists. Work 2017, 57, 573-593. [CrossRef] [PubMed]

9. Garbin, A.J.Í.; Barreto Soares, G.; Moreira Arcieri, R.; Garbin, C.A.S.; Siqueira, C.E. Musculoskeletal disorders and perception of working conditions: A survey of Brazilian dentists in São Paulo. Int. J. Occup. Med. Environ. Health 2017, 30, 367-377.

10. Bruers, J.J.M.; Trommelen, L.E.C.M.; Hawi, P.; Brand, H.S. Musculoskeletal disorders among dentists and dental students in the Netherlands. Ned. Tijdschr. Tandheelkd. 2017, 124, 581-587. [CrossRef]

11. Šćepanović, D.; Klavs, T.; Verdenik, I.; Oblak, Č. The Prevalence of Musculoskeletal Pain of Dental Workers Employed in Slovenia. Workplace Health Saf. 2019, 67, 461-469. [CrossRef]

12. Kalappa, S.; Shankar, R. A study on the influence of ergonomics on the prevalence of chronic pain disorders among dentists. Int. Surg. J. 2017, 4, 3873-3878. [CrossRef]

13. Natheer, A.R.; Hiba, E.K.; Lin, R.; Maryam, E.L.; Rawand, N.; Reem, Y.; Sausan, A.K. Musculoskeletal Pain among Different Dental Specialists in United Arab Emirates. OHDM 2016, 15, 292-298.

14. Taib, M.F.M.; Bahn, S.; Yun, M.H.; Taib, M.S.M. The effects of physical and psychosocial factors and ergonomic conditions on the prevalence of musculoskeletal disorders among dentists in Malaysia. Work 2017, 57, 297-308. [CrossRef]

15. Sakzewski, L.; Naserud-Din, S. Work-related musculoskeletal disorders in Australian dentists and orthodontists: Risk assessment and prevention. Work 2015, 52, 559-579. [CrossRef]

16. Ramírez-Sepúlveda, K.A.; Gómez-Arias, M.Y.; Agudelo-Suárez, A.A.; Ramírez-Ossa, D.M. Musculoskeletal disorders and related factors in the Colombian orthodontists' practice. Int. J. Occup. Saf. Ergon. 2021, 1, 1-10. [CrossRef]

17. De Bruyne, M.; Van Renterghem, B.; Baird, A.; Palmans, T.; Danneels, L.; Dolphens, M. Influence of different stool types on muscle activity and lumbar posture among dentists during a simulated dental screening task. Appl. Ergon. 2016, 56, 220-226. [CrossRef]

18. De Grado, G.F.; Denni, J.; Musset, A.M.; Offner, D. Back pain prevalence, intensity and associated factors in French dentists: A national study among 1004 professionals. Eur. Spine J. 2019, 28, 2510-2516. [CrossRef]

19. Bhandari, A.J.; Gada, V.H.; Manda, A.M.; Joshi, A.N.; Chaudhari, P.R.; Toshniwal, D.G. Dental operator's posture and position. Int. J. Dent. Health Sci. 2015, 2, 1261-1267.

20. Ahearn, D.J.; Sanders, M.J.; Turcotte, C. Ergonomic design for dental offices. Work 2010, 35, 495-503. [CrossRef]

21. Sakzewski, L.; Naserud-Din, S. Work-related musculoskeletal disorders in dentists and orthodontists: A review of the literature. Work 2014, 48, 37-45. [CrossRef]

22. Voudouris, J.C.; Suri, S.; Tompson, B.; Voudouris, J.D.; Schismenos, C.; Poulos, J. Self-ligation shortens chair time and compounds savings, with external bracket hygiene compared to conventional li-gation: Systematic review with meta-analysis of randomized controlled trials. Dent. Oral Craniofac. Res. 2018, 4, 1-10. [CrossRef]

23. Pamukçu, H.; Özsoy, O.P. Indirect Bonding Revisited. Turk. J. Orthod. 2016, 9, 80-86. [CrossRef] [PubMed]

24. Glisic, O.; Hoejbjerre, L.; Sonnesen, L. A comparison of patient experience, chair-side time, accuracy of dental arch measurements and costs of acquisition of dental models. Angle Orthod. 2019, 89, 868-875. [CrossRef] [PubMed]

25. Bud, M.; Jitaru, S.; Lucaciu, O.; Korkut, B.; Dumitrascu-Timis, L.; Ionescu, C.; Cimpean, S.; Delean, A. The advantages of the dental operative microscope in restorative dentistry. Med. Pharm. Rep. 2021, 94, 22-27. [CrossRef] 